\title{
SELEÇÃO DE DIRETORES ESCOLARES NO ESTADO DO RIO DE JANEIRO: HIBERNAÇÃO DA DEMOCRACIA NA AGENDA POLÍTICA DOS MUNICÍPIOS
}

http://dx.doi.org/10.5902/2318133854740

\author{
Daniela Patti do Amaral ${ }^{1}$ \\ Marcela Moraes de Castro²
}

\begin{abstract}
Resumo
Neste artigo apresenta-se uma análise da participação da comunidade nos processos de seleção de diretores em municípios do Estado Rio de Janeiro considerados de baixa fidelidade normativa. O Plano Nacional de Educação - PNE - constitui-se como a política indutora da regulamentação da gestão democrática e a pesquisa operou-se no desdobramento desse com relação aos municípios. A partir do pressuposto da participação para uma escola democrática, problematizamos o sentido de comunidade que circula no campo educacional e nas políticas. Sobre o processo de hibernação da gestão democrática ponderamos sobre os efeitos dessa ação do município a partir do PNE. Apesar de regulamentada a gestão, não é possível situar os municípios pesquisados no contexto que tende à democracia.

Palavras-chave: gestão democrática; participação; seleção de diretores; consulta pública; eleição.
\end{abstract}

\section{SELECTION OF PRINCIPALS IN THE STATE OF RIO DE JANEIRO: THE HIBERNATION OF DEMOCRACY IN THE POLITICAL AGENDA OF THE MUNICIPALITIES}

\begin{abstract}
This article focuses on community participation in the selection process of school principals in municipalities in the state of Rio de Janeiro, considered to be of low ordering fidelity. The National Education Plan - PNE - constitutes the policy that induces the regulation of democratic management and the analysis operates in the unfolding of this policy in relation to the municipalities. Understanding participation as a key of a democratic school, we problematize the sense of community that circulates in the educational field and in the official texts. To analyze the hibernation process of democratic management, we ponder the effects of this municipality action from the policy of PNE. Although management is regulated, it is not possible to place these municipalities in the context that tends towards democracy.

Key-words: democratic management; participation; principals selection; public consultation; election.
\end{abstract}

\footnotetext{
${ }_{1}$ Universidade Federal do Rio de Janeiro, Brasil. E-mail: danielapatti.ufri@gmail.com.

2 Universidade Federal do Rio de Janeiro, Brasil. E-mail: marcelamoraesdecastro@gmail.com.
} 


\section{Introdução}

1 creditamos que a participação da comunidade na seleção de diretores de escolas públicas é um dos pré-requisitos para uma escola de vivências democráticas. Lima (2018) destaca que uma escola democrática não está garantida de uma vez por todas e exigirá processos permanentes de consolidação e de aprofundamento. Como processo esta exige estruturas e pré-requisitos democráticos que instituem-se por meio de arranjos espaço-temporais, articulados pelas ações dos sujeitos, resultantes de práticas participativas, imbuídas de poder decisório.

Nesse contexto, como objeto de atenção da análise sobre as formas de participação da comunidade nos processos de seleção de diretores escolares, focamos nos municípios do Estado Rio de Janeiro e nos preocupamos com a seguinte questão: de que forma os legisladores, na oficialização de seus dispositivos legais, trazem para a cena política, no contexto da política democrática, a participação da comunidade no processo de seleção de diretores de escolas públicas? Neste artigo interessa-nos problematizar os municípios que induzem o PNE (Brasil, 2014) à hibernação (Castro, 2019). Para isso apresentamos a situação de dez, de um total de 92 municípios do Estado.

As legislações analisadas oscilam entre os termos eleição e consulta pública, marcando uma tensão no campo da pesquisa em políticas públicas educacionais e, especificamente sobre gestão democrática, que diz respeito aos limites e possibilidades de atuação política da comunidade nas duas formas que engendram a participação. Por que a escolha, pelos legisladores do município, entre uma e outra forma? Como se materializa a participação da comunidade na seleção de diretores por meio da eleição e, no outro caso, por meio da consulta?

\section{PNE e gestão democrática: dimensão teórica da comunidade que participa}

Pelo PNE (Brasil, 2014) definiu-se que os entes federados aprovem legislação específica que promova e discipline a gestão democrática da educação pública para seus sistemas de ensino. A seleção de diretores para as escolas públicas deverá estar associada a critérios técnicos de mérito e desempenho e à consulta pública à comunidade escolar, no âmbito das escolas públicas. Tendo em vista a diversidade do país o cenário para a participação da comunidade escolar no processo é complexo e configura-se como um campo fértil de pesquisa e análise dos contextos e sentidos atribuídos à gestão democrática da educação.

Sobre a definição de quem participa na escola Paro (2007) afirma que a comunidade escolar se define pelo "conjunto de pais/famílias que, ou por residirem no âmbito regional servido por determinada escola, ou por terem fácil acesso físico a ela, são usuários, efetivos ou potenciais de seus serviços" (p. 256). No sentido de pensar os destinatários de uma política este é um conceito de comunidade que permeia os ordenamentos legais sobre políticas educacionais e estrutura a instituição escolar, mas não oferece soluções para pensar uma escola democrática, na medida em que a comunidade fica definida como uma categoria volátil, distanciada da prática da ação no espaço institucional escolar.

Desse modo, a partir de Paro (2007), ampliamos o debate: defendemos como perspectiva que o que caracteriza a comunidade escolar são demandas similares, inicialmente díspares que, quando articuladas, identificam os sujeitos de um coletivo. Consideramos a comunidade como uma diversidade de sujeitos que, por meio dessas 
identificações múltiplas, atuam na instituição escolar sob a forma de coletivos. Logo, se há uma pluralidade de indivíduos, acreditamos que a escola caracteriza-se por uma diversidade de grupos, articulados a demandas específicas. O processo de formação dos coletivos passa por uma dimensão subjetiva individual que, somente assume um sentido de grupo, quando outras demandas particulares - também individuais - articulam-se no sentido de pensar os objetos e as práticas da instituição escolar. Nesse movimento a atuação do indivíduo ganha dimensão política, como resultado de uma articulação de um grupo que tem a capacidade de representar as paixões que, como afirmam Laclau e Mouffe (2004), representam formas coletivas de identificação, mobilizadoras das demandas. Assim, a comunidade objetiva-se na ação prática, territorializa-se na escola e é identificada no espaço institucional que, muito embora possa assumir relação com o âmbito regional, lugar de moradia, excede-o numa outra forma de identificação: aquela do movimento que justifica a luta por determinadas ideias, a disputa por projetos educacionais específicos, no lugar de destinatárias de políticas.

Esta perspectiva anuncia-se potente em nosso debate pois, para uma escola democrática, em que seja considerada a participação dos sujeitos como seu mecanismo, a comunidade, no modo a que vimos defendendo - sujeitos da ação política democrática somente existe quando associada, tanto às possibilidades institucionais que requerem a participação dos sujeitos no espaço escolar, quanto às possibilidade de formas de identificação destes sujeitos na instituição.

Relacionamos comunidade escolar aos mecanismos coletivos de participação como os conselhos escolares, as associações de pais, mestres e funcionários não docentes, os grêmios estudantis, os conselhos de classe e àquelas relativas à escolha democrática dos dirigentes escolares, considerando a necessidade de pluralizar outros coletivos que possibilitem a participação, pois quanto mais possibilidades de identificação, maior a possibilidade de participação.

\section{Percurso metodológico}

Os 92 municípios do Estado do Rio de Janeiro dividem-se em oito regiões governo: Metropolitana, Noroeste Fluminense, Norte Fluminense, Baixadas Litorâneas, Serrana, Centro-Sul Fluminense, Médio Paraíba e Costa Verde. Na perspectiva de analisar a participação da comunidade no processo de seleção de diretores de escolas públicas realizamos um levantamento nos endereços eletrônicos das prefeituras, câmaras de vereadores e secretarias municipais de educação dos 92 municípios do Estado no período de março de 2018 a julho de 2020. Analisamos as leis orgânicas e os planos municipais de educação dos 92 municípios e localizamos as legislações que disciplinam o processo de seleção de diretores em trinta e oito deles: Aperibé; Areal; Bom Jardim; Cabo Frio, Cambuci; Campos dos Goytacazes; Carmo; Casimiro de Abreu; Comendador Levy Gasparian; Cordeiro; Duas Barras; Duque de Caxias; Iguaba Grande; Itaguaí; Japeri; Macaé; Natividade, Nilópolis; Niterói; Nova Friburgo, Nova Iguaçu; Paraíba do Sul; Paty do Alferes; Paraty; Piraí; Porto Real; Quatis; Queimados; Rio das Flores; Rio de Janeiro; São Fidélis; São Francisco do Itabapoana; São Pedro da Aldeia; Saquarema, Seropédica; Sumidouro; Três Rios e Valença. 
Para disciplinar o processo de seleção de diretores de escolas públicas a legislação que regulamenta deve estar alinhada ao PNE (Brasil, 2014), à Constituição do Estado do Rio de Janeiro (Rio de Janeiro, 2016); ao Plano Estadual de Educação; à Lei Orgânica dos municípios e aos planos municipais de educação - PME -, tendo em vista a competência legislativa de cada matéria. A meta 19 do PNE (Brasil, 2014) determina a seleção de diretores por critérios técnicos de mérito e desempenho com participação da comunidade escolar. A gestão democrática da educação do ensino público está presente na Constituição estadual sem, contudo, mencionar as formas de seleção de diretores de escolas públicas.

Esta análise das legislações municipais - lei orgânica; plano municipal de educação e legislação que regulamenta a seleção de diretores - permitiu formar uma cartografia do movimento político acerca da participação da comunidade nos processos de seleção de diretores. O fato de não localizarmos legislações nos demais municípios do Estado indica que o processo de seleção de diretores pode ainda não ter sido regulamentado ou a legislação não foi disponibilizada nos endereços eletrônicos oficiais mencionados. Dentre os 38 textos localizados nos municípios selecionamos oito para o aprofundamento da análise.

Acreditamos que o levantamento pode apontar infidelidades normativas no município que produzem, também, variações da possibilidade da comunidade participar. Nesta análise compreendemos que há aproximações e afastamentos acerca das formas de participação da comunidade na seleção de diretores e estes movimentos estão relacionados a diferentes momentos políticos de cada município, que mantém relação com uma trajetória histórica de uma cultura política local, a qual possibilita em maior ou menor escala a participação da comunidade no processo.

\section{As políticas de baixa fidelidade normativa: participação da comunidade e a produção de um consenso}

Agrupamos os 38 municípios analisados em três categorias: um primeiro grupo, com elevado grau de fidelidade normativa, contempla aqueles que mantêm uma perspectiva de alinhamento às determinações postas nas legislações (Amaral; Castro, 2020). Sobre este poderíamos inferir que o município, independentemente do arranjo político do momento presente, segue um mesmo percurso normativo com relação à seleção de diretores, um movimento que poderia ser justificado pela trajetória histórica local. São municípios que operam diferentemente da lógica definida por Cunha (1997, p. 1) como zigue-zague da política, que se constituem de "oscilações resultantes do fato de que cada ministro ou secretário de educação tenha a sua idéia 'salvadora' para a crise da educação, o seu plano de carreira, a sua proposta curricular, o seu tipo de arquitetura escolar, as suas prioridades".

O segundo grupo apresenta um grau intermediário de fidelidade normativa, pois nas três legislações consultadas demonstram oscilações no percurso que define o processo de seleção de diretores, ora como consulta, ora como eleição. É instigante observar que nesse grupo as disputas entre os sujeitos que transitam nos espaços da política ficam evidenciadas no percurso legislativo que traduz o texto da política, muito embora esse 
quadro, caracterizado pelo desalinho legislativo no município, não induza, necessariamente, a uma resposta baixa na escala de democracia, quando se trata de olhar para o processo de seleção de diretores que pode se regulamentada através de eleições diretas, ampliando as formas de participação da comunidade (Amaral, no prelo).

Por fim, o terceiro grupo é considerado de baixa fidelidade normativa, nos quais a matéria não aparece nas leis orgânicas, nem no PME, sendo posta em cena somente nas legislações mais recentes que regulamentaram o processo de seleção de diretores, demonstrando um cenário em que os momentos e movimentos políticos anteriores desses municípios não trouxeram para a pauta da agenda política o debate sobre a seleção de diretores de escolas públicas. Esse cenário que é o foco do presente artigo pode ser visualizado em Areal, Cambuci, Comendador Levy Gasparian, Cordeiro, Duas Barras, Nilópolis, Nova Iguaçu, Saquarema, Três Rios e Valença. Neste grupo, cinco municípios Areal, Cambuci, Cordeiro, Duas Barras e Valença - homologaram a eleição, enquanto quatro municípios - Comendador Levy Gasparian, Nova Iguaçu, Saquarema e Três Rios homologaram a consulta para o processo de seleção de diretores.

Aqui é possível uma consideração: a dissonância no alinho da política que resulta na eleição como forma de participação da comunidade não é garantidora de uma elevada escala de democracia. Por ora, a conjuntura nos faz inferir que o arranjo político que trata da seleção de diretores com a participação da comunidade é contextual, muito mais caracterizado pelos sujeitos que ocupam lugar na cena política no momento presente dos municípios e que numa escala que tende à democracia encontraram a brecha com uma melhor organização de poder, como explicam Mouffe e Errejón (2016), na construção de um texto político mais tendente à democracia, mas de caráter instável no que diz respeito à trajetória histórica do município. Logo, pode, tanto assumir um contexto contingente, como pode começar a fundamentar novas práticas democráticas.

No quadro 1 apresenta-se o grupo que denominamos municípios de baixa fidelidade normativa. Nestes a participação da comunidade na seleção de diretores não aparece nas leis orgânicas, nem no PME, sendo posta em cena somente nas legislações mais recentes que regulamentaram o processo de seleção de diretores. Inferimos que esse movimento recente tenha sido induzido pela estratégia 19.1 do PNE (Brasil, 2014), que determina a priorização de repasse de transferências voluntárias da União aos municípios que aprovem legislação específica para a nomeação dos diretores de escola contemplando critérios técnicos de mérito e desempenho, bem como a participação da comunidade escolar.

O quadro 1, sobre a participação da comunidade no processo de seleção de diretores, demonstra um emaranhado de normativas que incluem diversas formas de legislar: lei, decreto e resolução. Conforme Mendonça (2001, p. 98) "a posição hierárquica do instrumento legal utilizado na institucionalização de diretrizes políticas na área educacional parece ser um fator indicador da menor ou maior perenidade dessas diretrizes". Utilizamos uma metáfora de uma escala que regula a democracia e está relacionada com a participação concedida à comunidade por uma determinada instância subnacional. A opção por uma peça legislativa significa a escala da participação da comunidade escolar e local, dos destinatários da política no processo, pois para cada ordenamento, um modo de participação está previsto. 
Quadro 1 -

Legislações sobre seleção de diretores escolares.

\begin{tabular}{|c|c|c|c|c|}
\hline Município & Lei orgânica & PME & $\begin{array}{l}\text { Legislação que } \\
\text { regulamentou a } \\
\text { seleção de diretores }\end{array}$ & $\begin{array}{l}\text { Formas de } \\
\text { participação da } \\
\text { comunidade }\end{array}$ \\
\hline Areal & Não menciona & Não menciona & Lei n. 945/2017 & Eleição \\
\hline Cambuci & Não menciona & Não menciona & Decreto n. 1.413/2019 & Eleição \\
\hline $\begin{array}{l}\text { Comendador } \\
\text { Levy Gasparian }\end{array}$ & Não menciona & Não menciona & $\begin{array}{c}\text { Lei n. } 881 / 2015 \\
\text { Lei n. 933/2016 } \\
\text { Decreto n. 1.621/2017 }\end{array}$ & Consulta \\
\hline Cordeiro & Não menciona & Não menciona & $\begin{array}{l}\text { Lei n. } 2.084 / 2016 \\
\text { Decreto n. 114/2017 }\end{array}$ & Eleição \\
\hline Duas Barras & Não menciona & Não menciona & Lei n. 1.272/2017 & Eleição \\
\hline Nilópolis & Não menciona & Não menciona & $\begin{array}{c}\text { Resolução Semed n. } \\
1 / 2020\end{array}$ & Consulta \\
\hline Nova Iguaçu & Não menciona & Não menciona & $\begin{array}{c}\text { Decreto } \mathrm{n} . \\
11.021 / 2017 \\
\text { Resolução Semed } \mathrm{n} . \\
9 / 2017\end{array}$ & Consulta \\
\hline Saquarema & Não menciona & Não menciona & Lei n. 1512/2016 & Consulta \\
\hline Três Rios & Não menciona & Não menciona & Lei n. 4.425/2017 & Consulta \\
\hline Valença & Não menciona & Não menciona & Resolução n. 3/2015 & Eleição \\
\hline
\end{tabular}

Fonte: autoras a partir das consultas aos endereços eletrônicos dos municípios.

Embora a omissão dos municípios evidencie o desalinho com as políticas nacionais, num movimento que deixa um hiato entre o PNE (Brasil, 2014), a lei orgânica e o PME dos referidos municípios, é possível observar o preenchimento da lacuna no apagar das luzes para o cumprimento do prazo de elaboração ou adequação dos planos municipais ao PNE (Brasil, 2014), estabelecido para o dia 24 de junho de 2015.

Sobre o cumprimento da meta 19 ressaltamos que o município de Valença é aquele que atende às exigências do PNE (Brasil, 2014) com o menor tempo de tradução de sua política, mas com cerca de quase cinco meses de atraso. Entretanto, esta exigência se realizou sem debate com a comunidade com prerrogativa de decisão do executivo na proposição de uma resolução. Chama atenção que os demais municípios extrapolam em largo prazo o que foi estabelecido pelo PNE (Brasil, 2014) e, no que diz respeito à seleção de diretores, a ação de elaborar um ordenamento remete-nos à ideia de criação de um template que procura atender ao PNE (Brasil, 2014) como norma, em decorrência do repasse de recursos, mais do que estabelecer um debate político sobre o significado do processo de seleção de diretores, como possibilidade de democratização da instituição escolar. 


\section{Os textos políticos dos municípios e a participação da comunidade}

Areal tornou-se município em 1992. Sua lei orgânica, publicada em 1995, determina a organização da gestão democrática do ensino público com a participação da sociedade na formação da política educacional e no acompanhamento de sua execução; a criação de mecanismo para prestação dos recursos destinados à educação; a participação de estudantes, professores, pais e funcionários, pelo funcionamento do Conselho Comunitário, em todas as unidades escolares, com o objetivo de acompanhar o nível pedagógico da escola, segundo normas dos conselhos estadual e municipal de educação. Não há menção no documento sobre processo de seleção de diretores escolares. Na lei que aprovou o Plano Municipal de Educação (2016) não consta a gestão democrática das escolas como princípio e a meta 19 reproduz a meta nacional.

Somente em 2017 a seleção de diretores foi regulamentada pela lei n. 945/2017 (Areal, 2017) que, no entanto, não discrimina as formas de participação da comunidade no processo e delibera que o diretor será eleito "pelo voto direto e secreto de servidores lotados nas unidades onde ocorrerá o pleito, alunos e pais de alunos que estiverem em condições plenas para o exercício do voto" (Areal, 2017). Pelo texto não é possível compreender quais seriam as condições plenas mencionadas. Nesse contexto, há uma lacuna normativa na política educacional sobre a seleção de diretores que aponta para uma baixa fidelidade além de uma omissão dos legisladores sobre a matéria. Adicionalmente, a ementa da lei dispõe sobre "eleição de diretores e diretores adjuntos", mas o parágrafo $2^{\circ}$ e outros artigos do ordenamento mencionam sobre a realização de "consultas" e "processo consultivo".

Município desde o início do século 20, Cambuci aprovou sua lei orgânica em 1990 e não há menção à gestão democrática da educação no documento. O PME, aprovado em 2016, não apresenta a gestão democrática como princípio, bem como não há meta ou estratégias sobre o tema. A seleção de diretores não é mencionada no documento, mas foi regulamentada pelo decreto n. 1.413 , de 20 de dezembro de 2019, que dispõe sobre o estabelecimento de processos consultivos para a eleição em gestão democrática de diretores gestores das unidades escolares (Cambuci, 2019). Observamos o silenciamento da matéria durante um longo período e acreditamos que a aprovação do PNE (Brasil, 2014), vinculando repasses financeiros para os municípios que tivessem sistematizado a matéria tenha sido um forte indutor para a ação do executivo municipal, tendo em vista a aprovação por decreto. Nesse aspecto, além de baixa fidelidade normativa, há ainda uma baixa escala de democracia pela aprovação sem diálogo com a casa legislativa em ação unipessoal do poder executivo. O referido decreto determina que são eleitores os membros do magistério e os servidores públicos administrativos; os alunos matriculados na unidade escolar que tenham, no mínimo, doze anos de idade; e um responsável por aluno menor de doze anos.

A lei orgânica de Comendador Levy Gasparian foi aprovada em 30 de junho de 1993. A organização da gestão democrática do ensino público municipal é mencionada na lei ao fazer referência à estruturação do sistema municipal de ensino. Dentre as diretrizes da gestão democrática do ensino não consta a seleção de diretores escolares. No Plano Municipal de Educação, aprovado em 2009, pela lei n. 673, de dezembro de 2009, consta a meta 19 destinada à gestão democrática, no entanto, a estratégia 19.1 reproduz o texto nacional ao afirmar que será priorizado "o repasse de transferências voluntárias da União na área da educação para os entes federados que tenham aprovado legislação específica 
que regulamente a matéria na área de sua abrangência, respeitando-se a legislação nacional", furtando-se de fazer uma tradução local do texto nacional. Em 13 de setembro de 2017 o prefeito sancionou o decreto n. 1.621, que dispõe sobre o estabelecimento de processos consultivos para a indicação de diretores escolares sendo considerados eleitores os membros do magistério e os servidores públicos com funções administrativas; os alunos matriculados na unidade escolar que tenham, no mínimo, quatorze anos de idade e um responsável por aluno menor de quatorze anos. Nesse município ressaltamos que o debate sobre a seleção de diretores dado pelas leis publicadas em 2015 e 2016 cedeu lugar a um decreto. Ainda assim, a forma de seleção de diretores prosseguiu assumindo a consulta à comunidade, o que não significa dar a ela o direto de decidir. Nesta composição é possível observar que o município vem decaindo na escala de democracia, quando consideramos a participação da comunidade como seu mecanismo.

Cordeiro teve sua lei orgânica aprovada em 5 de abril de 1990. A gestão democrática do ensino público está presente no artigo 282 da lei, sem fazer menção ao processo de seleção de diretores. Em seguida, em 26 de setembro de 1991, o município aprovou a lei n. 386, que institui o sistema de eleição direta para diretores de escolas municipais. No PME, aprovado em 2016, a presença da gestão democrática é observada na meta 17 sendo que a estratégia 17.1 determina a criação de legislação específica que regulamente a gestão democrática da educação estabelecendo, para a nomeação dos diretores e diretoras de escola, critérios técnicos de mérito e desempenho, bem como a participação da comunidade escolar. No entanto, não foi especificado como ocorrerá o processo de seleção de diretores contemplando a participação da comunidade. Ainda em 2016 foi aprovada a lei n. 2.084, que dispõe sobre a gestão democrática do sistema municipal de ensino. Conforme o artigo 18 a eleição para a função de diretor das escolas públicas segue o regulamento disposto pela lei n. 389/91 (Cordeiro, 1991) que institui o sistema de eleição direta para preenchimento dos cargos de diretor de escolas. Apesar da matéria não ser mencionada na lei orgânica o município aprovou lei que disciplina a eleição de diretores um ano depois de sua publicação, sendo que esta permanece em vigência há quase 30 anos. Conforme a lei n. 389/91 (Cordeiro, 1991), o voto será ponderado na proporção de 50\% do total de votantes para professores e cinquenta por cento para os demais eleitores: funcionários, pais de alunos e alunos matriculados a partir do $6^{\circ}$ ano do ensino fundamental I.

A lei orgânica de Duas Barras foi aprovada em 5 de abril de 1990, sem nenhuma referência à gestão democrática da educação pública. O PME, aprovado em 2015, destina a meta 19 à gestão democrática determinando a aprovação de lei que regulamente a seleção de diretores com participação da comunidade escolar. Em 30 de outubro de 2017 foi aprovada a lei n. 1272, que dispõe sobre a instituição da gestão democrática no sistema municipal. Conforme a lei a escolha de diretores de escola ocorrerá com participação efetiva da comunidade escolar, adotando o sistema eletivo, mediante voto direto e secreto e são considerados eleitores os profissionais da educação em exercício na escola; alunos regularmente matriculados que tenham no mínimo doze anos de idade ou estejam cursando do $6^{\circ}$ ano em diante; pai ou responsável legal de alunos menores de 12 anos.

Em Nilópolis, tanto a lei orgânica aprovada 1990, bem como PME sancionado em 2015, não mencionam o processo de seleção de diretores. A resolução Secretaria Municipal de Educação n. 1, de 28 de fevereiro de 2020, estabeleceu o processo de consulta pública 
de seleção de gestores das unidades escolares. Estão aptos a votar todos os profissionais das unidades escolares: funcionários efetivos e contratados; um responsável legal por aluno matriculado; alunos matriculados com idades iguais ou acima de doze anos; cada representante do Conselho Escola Comunidade terá direito a um voto.

Nova Iguaçu aprovou sua lei orgânica em 1990 e seu PME em 2015, sendo que os dois documentos não mencionam a forma de seleção de diretores. Em 26 de julho de 2017 foi publicado o decreto n. 11.021, que dispõe sobre o processo de consulta à comunidade escolar para seleção de gestores das unidades. O colégio eleitoral será formado por docentes; demais servidores efetivos; estudantes com pelo menos dez anos de idade e responsáveis legais pela matrícula dos estudantes menores de dezoito anos. Há uma confusão normativa no texto que deveria facultar o voto aos responsáveis legais pela matrícula de estudantes menores de dez anos e não de dezoito anos.

A lei orgânica de Saquarema, aprovada em 5 de abril de 1990, bem como a meta 19 e demais estratégias do Plano Municipal - lei n. 1.427, de 24 de junho de 2015, não mencionam o processo de seleção de diretores. O município aprovou a lei n. 1.512 em 10 de outubro de 2016, que estabelece normas para efetivação da gestão democrática. Conforme a lei são eleitores os membros do magistério e demais servidores efetivos; alunos com mais de dezesseis anos e responsáveis por alunos menores de dezesseis anos.

A lei orgânica de Três Rios, aprovada em 19 de novembro de 2002, e o Plano Municipal, lei n. 4.208, de 22 de junho de 2015, não mencionam a forma de seleção de diretores. A lei n. 4.425, aprovada em setembro de 2017, dispõe sobre o estabelecimento do pleito consultivo municipal para consulta pública para indicação de diretores e auxiliares de direção das unidades escolares. São eleitores os membros do magistério efetivos e os servidores públicos efetivos, os alunos que tenham, no mínimo dezesseis anos de idade, os alunos menores de 16 anos, representados por seus respectivos representantes legais.

A lei orgânica e o Plano Municipal de Educação de Valença, ambos aprovados em 2015, não mencionam a gestão democrática em seus textos. Posteriormente, Valença aprovou a resolução Secretaria Municipal de Educação n. 3, em novembro de 2015, que estabelece normas para eleição de diretor e diretor adjunto. São considerados eleitores os alunos a partir do $6^{\circ}$ ano do ensino fundamental, o responsável legal perante a unidade escolar dos alunos da creche ao $5^{\circ}$ ano do ensino fundamental, e todos os profissionais da educação lotados em efetivo exercício na escola/creche específica.

\section{PNE: da hibernação da democracia na escola à sua indução}

Nestes municípios, caracterizados como de baixa fidelidade normativa, chama-nos atenção o processo de regulamentação das políticas que tratam da gestão democrática na escola e, principalmente àqueles relacionados com o processo de seleção de diretores. Logo, entendemos que a omissão à regulamentação da referida meta constitui-se como o momento no qual estes municípios conduzem a política que propõe a democratização da escola - o PNE (Brasil, 2014) - à hibernação, como pondera Castro (2019), pois entre o prazo definido para o alinhamento da política dos entes federados sobre a gestão democrática há, em todos os dez municípios apresentados, um atraso relativo à elaboração de um ordenamento que faça cumprir a meta 19. 
Entretanto, o processo de hibernação da política, produzido pelo interesse dos sujeitos políticos, não retira da cena política um ordenamento, mas opera com ele num Estado que o aproxima de uma quase inatividade, restringindo um conjunto de processos que dele decorreriam. Assim, o PNE (Brasil, 2014) levado à hibernação, refreia a escola democrática quando não são regulamentadas as peças legislativas que comporiam uma arquitetura política relacionada ao processo de seleção de diretores com a participação da comunidade.

É possível considerar que condições adversas induzem um ordenamento à hibernação: um contexto político no qual a casa legislativa esteja mais favorável à atuação do executivo na escolha do diretor, na tentativa de manter a ação do executivo com exclusividade na decisão; pouca atenção da sociedade civil a uma pauta política específica, permitindo a atenção de outros grupos à política; interesse do Estado em movimentar a política conforme perspectivas em alinho com politicas que extrapolam um contexto específico de cada ente federado, dentre outros. De outro modo, como a hibernação da política não indica uma inércia de seu conteúdo político (Castro, 2019), pois no processo de sua elaboração os atores do contexto de produção de texto conseguem propor políticas de caráter vinculante, como é o caso da meta 19 do PNE (Brasil, 2014), há um limite para a manutenção do seu Estado letárgico. Ou seja, quando analisado o PNE (Brasil, 2014) neste sentido é possível verificar que a estratégia 19.1 faz o nexo de ligação entre o repasse de transferências da União aos entes federados atando o cumprimento de um pelo outro.

Esse elemento permite que entendamos, tanto o atraso da feitura dos ordenamentos, quanto a opção por um ou outro tipo de legislação, quando tentamos compreender os municípios que praticam numa escala mais ou menos elevada de democracia. Dos dez municípios citados seis regulamentaram uma lei para a seleção de diretores, o que indica que estes assumem uma escala de democracia mais ampliada, na medida em que o que caracteriza a democracia - a participação, o debate, a disputa por projetos distintos - está dado pelo processo de construção de uma lei. Mais provocativo ainda é pensar que dos seis municípios, três aprovam a eleição para o processo de escolha de diretores, o que indica a participação da comunidade sem a interferência do executivo no processo, e três permanecem com a consulta que pode, ou não, considerar a escolha da comunidade como a decisão do diretor para a função.

Nesse sentido, consideramos que o manejo de hibernação de uma política pode apresentar limites, sejam eles produzidos pelo próprio contexto do ordenamento, como foi o caso apresentado, ou quando se configuram inscrições espaço temporais em que o objeto do ordenamento passa a traduzir algum problema social, como ocorreu com as ocupações estudantis no ano de 2016, na demanda que estabeleceu a lei de seleção de diretores no Estado do Rio de Janeiro (Rio de Janeiro, 2016), com participação exclusiva da comunidade escolar.

\section{Considerações finais}

Assumindo a participação como mecanismo da democracia na gestão da escola, investimos na tentativa de ampliar o conceito de comunidade escolar, pois, interessa-nos pensar na teoria que pode intervir na política enquanto ação cotidiana, pela mobilização de sujeitos por meio da participação nos espaços institucionalizados que constituem a política democrática como, no caso, é a escola e nos processos de seleção de diretores. 
Como apresentado pelos ordenamentos que sistematizam a gestão democrática nos municípios caracterizados como de baixa fidelidade não é possível observar uma chave de resposta na regulamentação da gestão democrática. Os ordenamentos oscilam em paradoxos entre o caráter do ordenamento que sistematiza a seleção de diretores e a participação da comunidade. Este exemplo pode ser evidenciado pelos municípios que apresentam o decreto como elemento que estrutura a participação da comunidade num processo de eleição - e não consulta - de diretores, e uma resolução que a também segue a mesma opção. De outro modo é possível observar uma lei, ordenamento que se constrói numa perspectiva de caráter mais democrático, na opção pela consulta à comunidade, conforme o texto do PNE (Brasil, 2014).

\section{Referências}

AMARAL, Daniela Patti do. Seleção de diretores escolares no Estado do Rio de Janeiro: textos legais e (in)fidelidades normativas. In: AMARAL, Daniela Patti; CASTRO, Marcela Moraes de (orgs.). Políticas educacionais no Estado do Rio de Janeiro: provocações sobre democracia e gestão da escola pública. Brasília: Anpae (no prelo).

AMARAL, Daniela Patti; CASTRO, Marcela Moraes de. Seleção de diretores escolares no Estado do Rio de Janeiro: a participação da comunidade no (con)texto político. Roteiro, Joaçaba, v. 45, 2020, p. 1-22.

AREAL. Lei $n$. 945 de 23 de agosto de 2017: estabelece normas para eleição de diretores e diretores adjuntos das escolas municipais. Areal: Prefeitura Municipal, 2017.

BRASIL. Constituição da República Federativa do Brasil. Brasília: Presidência da República, 1988.

BRASIL. Lei n. 13.005 de 25 de junho de 2014: aprova o Plano Nacional de Educação PNE - e dá outras providências. Disponível em http://www.planalto.gov.br/CCIVIL_03/_Ato2011-2014/2014/Lei/L13005.htm. Acesso em 5 maio 2018.

CAMBUCl. Decreto n. 1413 de 20 de dezembro de 2019: dispõe sobre o estabelecimento de processos consultivos para a eleição em gestão democrática de diretores gestores das unidades escolares. Cambuci: Prefeitura Municipal, 2019.

CASTRO, Marcela. O silenciamento da participação da juventude na seleção de diretores no PEE/RJ. Revista Contemporânea de Educação, Rio de Janeiro, v. 14, n. 31, 2019, p. 143-161.

COMENDADOR LEVY GASPARIAN. Lei n. 993 de 27 de outubro de 2016: dispõe sobre a gestão democrática do sistema municipal de ensino. Comendador Levy Gasparian: Prefeitura Municipal, 2016.

CORDEIRO. Decreto n. 114 de 26 de outubro de 2017: dispõe sobre a regulamentação necessa'ria para o sistema de eleição diretoa para preenchiemtno das funções de diretor e diretor adjunto das uniadades escoalres. Cordeiro: Prefeitura Municipal, 2017.

CORDEIRO. Lei n. 2084 de 22 de novembro de 2016: dispõe sobre a instituição da gestão democrática no sistema municipal de ensino público. Cordeiro: Prefeitura Municipal, 2016.

CUNHA, Luiz Antônio. Ensino médio e ensino profissional: da fusão à exclusão. REUNIÃO ANUAL DA ANPED, 20, 1997. Anais ... Caxambu: Anped, 1997. 
DUAS BARRAS. Lei municipal n. 1.272 de 30 de outubro de 2017: dispõe sobre a instituição da gestão democrática no sistema municipal de ensino. Duas Barras: Prefeitura Municipal 2017.

LACLAU, Ernesto. Mouffe, Chantal. Hegemonía y estratégia socialista: hacia uma radicalización de la democracia. Buenos Aires: Fondo de Cultura Económica, 2004.

LIMA, Licínio Carlos. Entrevista. Movimento-Revista de Educação, Niterói, v. 8, n. 8, 2018, p. 244-256.

MENDONÇA, Erasto Fortes. Estado patrimonial e gestão democrática do ensino público no Brasil. Educação \& Sociedade, São Paulo, v. 22, n. 75, 2001, p. 84-108.

NILÓPOLIS. Resolução Semed $n$. 1 de 28 de fevereiro de 2020: estabelece o processo de consulta pública de seleção de gestores das unidades escolares da rede pública do sistema municipal de ensino de Nilópolis e dá outras providências. Nilópolis: Prefeitura Municipal, 2020.

NOVA IGUAÇU. Decreto n. 11.021 de 26 de julho de 2017: dispõe sobre o processo de consulta à comunidade escolar para seleção de gestores das unidades escolares da rede pública do sistema municipal de ensino da cidade de Nova Iguaçu e dá outras providências. Nova Iguaçu: Prefeitura Municipal, 2017.

NOVA IGUAÇU. Resolução Semed n. 9 de 24 de agosto de 2017: regulamenta o processo consultivo para a indicação de diretores gerais e diretores adjuntos das instituições de ensino integrantes da rede pública do sistema municipal de ensino do município de Nova Iguaçu. Nova Iguaçu: Prefeitura Municipal, 2017.

PARO, Vitor Henrique. Estrutura da escola e prática educacional democrática. REUNIÃO ANUAL DA ANPED, 30, 2007. Anais ... Caxambu: Anpae, 2007. Disponível em http://30reuniao.anped.org.br/trabalhos/GT05-2780--Int.pdf. Acesso em 12 jan. 2018.

RIO DE JANEIRO. Lei n. 7.299, de 3 de junho de 2016: dispõe sobre o estabelecimento de processos consultivos para a indicação de diretores e diretores adjuntos das instituições de ensino integrantes da rede da Secretaria de Estado de Educação e da Fundação de Apoio à Escola Técnica Faetec. Rio de Janeiro: DOE, 6 jun. 2016.

SAQUAREMA. Lei n. 1.512 de 10 de outubro de 2016: estabelece normas para efetivação da gestão democrática e valorização dos servidores públicos da educação e do magistério da Secretaria Municipal de Educação e Cultura de Saquarema. Saquarema: Prefeitura Municipal, 2016.

TRÊS RIOS. Lei n. 4.425 de 22 de setembro de 2017: dispõe sobre o estabelecimento do pleito consultivo municipal para consulta pública para indicação de diretores e auxiliares de direção das unidades escolares integrantes da rede municipal de ensino de Três Rios. três Rios: RJ, 2017. Três Rios: Prefeitura Municipal, 2017.

VALENÇA. Resolução n. 003/SME de 3 de novembro de 2015: estabelece normas para eleição de diretor e diretor adjunto das escolas/creches da rede municipal de ensino de Valença. Valença: Prefeitura Municipal, 2015.

Daniela Patti do Amaral é professora associada na Faculdade de Educação da Universidade Federal do Rio de Janeiro.

Orcid: https://orcid.org/0000-0002-9234-1843.

Endereço: Rua Dona Mariana, 185/503 - 22280-020 - Rio de Janeiro - RJ - Brasil.

E-mail: danielapatti.ufri@gmail.com. 
Marcela Moraes de Castro é pedagoga e técnica em assuntos educacionais na Universidade Federal do Rio de Janeiro.

Orcid: https://orcid.org/0000-0002-1507-8463.

Endereço: Rua Natalina, 15/ 102 - 20530-030 - Rio de Janeiro - RJ - Brasil.

E-mail: marcelamoraesdecastro@gmail.com.

Recebido em 7 de setembro de 2020.

Aceito em 12 de dezembro de 2020.

(c) (i) $(\theta)$ 